\title{
TRAJETÓRIAS DO DISCURSO LATINO-AMERICANISTA
}

Paulo-Edgar Almeida Resende

\begin{abstract}
Resumo: Para acompanhar as inconstâncias de que se revestem os esforços integracionistas, o autor se posiciona diante de pautas de estudo, a indicar que as relações internacionais se afirmam para os estudiosos como áreas de saber. Tendo como foco a América Latina, os discursos integracionistas latino-americanistas são problematizados no quadro do grande debate teórico.
\end{abstract}

Palavras-chave: alternativa; América Latina; integração.

Abstract: With the purpose of pointing out the inconsistencies present in integrationist movement, the author considers the interdisciplinary nature of international relations, basing his hypothesis on a large body of research. The Latin American approaches toward integration receive special focus, and are assessed within the framework of the larger theoretical debate.

Key words: alternative; Latin América; integration.

Novo lugar, no não-lugar. O Império sem Roma.

Hardt e Negri (2001)

$\mathrm{N}$ a busca de sentido do vocabulário integracionista, nada melhor do que partir de questões fundamentais: o que vem a ser a América Latina, o que ela tem sido, quais são as propostas da perspectiva de sua integração econômica, política, social e cultural? O que pode resultar da proximidade geográfica e dos trajetos iniciais assemelhados dos atuais estados nacionais, sob o estatuto de colônias ibéricas ou latinas? Do ponto de vista econômico, político, social e cultural, qual a persistência e consistência da suposta identidade de nascença? Na conclusão, levantase a possibilidade de alternativas, dadas as brechas existentes no sistema internacional. A proposta não é analisar os eixos básicos da política externa brasileira, mas o significado de dados da realidade do país, indispensáveis na análise mais extensa do que vem a ser a América Latina. A posição do Brasil com relação a vizinhos, seu enorme contingente populacional; sua dimensão territorial, superdotada de riquezas naturais; seu produto interno bruto, sua condição de glo- bal trader o tornam player de relevo na cena internacional. De modo altamente negativo, todavia, pesam sua democracia de participação restrita, tumultuada pela corrupção nas altas esferas, e seus desavantajados indicadores sociais nas escalas do Índice de Desenvolvimento Humano da ONU e do Índice Gini, mesmo em comparação com vizinhos do hemisfério sul.

\section{A PRODUÇÃO DA AMÉRICA LATINA}

O trabalho arqueológico e genealógico de reinvenção da América Latina, lida com a parafernália de informações e análises constitutivas do latino-americanismo, de origens diversas. Por essa via, o trajeto vai da mitologia e do romantismo à hegemonia. Ao discurso dos heróis de muitas lutas, mesclam-se discursos dos founders, da estirpe bolivariana, até os latino-americanistas de além-mar, não poucas vezes recheados de fantasias culturais, exotismos, etnocentrismos, paternalismos.

Levando-se em conta estilos e métodos de integração, vinculados a interesses, que impelem determinados grupos a disseminar suas idéias e tentar impor suas práticas de América Latina, América Ibérica, Terceiro Mundo, Oci- 
dente Cristão, é de vital importância a avaliação da compatibilidade destas representações com a amplitude e complexidade de projetos em curso: Mercosul, Comunidade Andina, Área de Livre Comércio Sul-Americana, Área de Livre Comércio das Américas, Mercosul-CAN/União Européia/Asean/China/Rússia/África, etc. Incluem-se no debate o bilateralismo e multilateralismo. São excludentes ou se complementam; a integração aberta prioriza quais relações inter-blocos.

Produzida no interior do Antigo Sistema Colonial, a América Latina não é inteligível se não estiver estabelecida no marco da longa duração e do grande espaço do sistema que a integrou, sob diferentes padrões, seja o da Conquista espanhola, seja o da Expansão portuguesa, da Hegemonia inglesa ou norte-americana. Com alguma licença, retiram-se categorias formuladas com objetivo analítico diverso, ao se nomear um padrão de integraçãoprimitiva (colonial), e um padrão de integração-ampliada. Este último chega aos dias atuais com a intensificação de processos de internacionalização dos mercados internos, corroendo fronteiras, nem bem constituídas. Tais referências não se fazem na perspectiva de adotar método de exposição sintética do que se passou. Não se trata de resumo apressado da intricada história latino-americana através dos séculos. A pretensão é valorizar, teórica e metodologicamente, princípios de integração que nos permitem ter idéia menos aleatória da natureza da realidade integrada. Sob o impacto da colonização, foi obtido certo grau, ainda que mínimo, de homogeneização. A dominação européia prefigurou a América Latina, que, a partir daí, deve a essa origem colonial alguns de seus traços fundamentais. O impacto originário do Ocidente configura sui generis integração, motu externo. O sistema colonial implica montagem do Novo Mundo, na condição de elemento constitutivo no processo de formação do capitalismo moderno, peça de um sistema, elemento decisivo na criação de prérequisitos do capitalismo industrial, tanto quanto na Europa a categoria original de acumulação primitiva apontava para a formação do mercado de trabalho. Com a diversificação regional, decorrente da vulnerável emancipação política dos novos Estados, atualizam-se os princípios de unidade extramuros. O localismo das Independências tem a aparência de desintegração regional. Mas, com a Revolução Industrial, a Europa modificou seu sistema de produção. A mudança levou a uma totalidade mais profunda e mais compacta, com a incorporação da periferia, embora em novos termos. Transformada em potência mundial, a Inglaterra não teve dificuldade de capitalizar os movimentos de independência no decorrer do século XIX, incapazes, por si mesmos, de organizar novo sistema de poder. A ruptura da ordem anterior fragmentou os grandes espaços coloniais, levando-os a se relacionar diretamente com a nova metrópole européia. Ao mesmo tempo, o hegemonismo programado da Doutrina Monroe exaltava o movimento pan-americanista. A política interna dos países latino-americanos passou a ser de interesse das autoridades dos Estados Unidos, com uma cadeia de intervenções. As relações mútuas se processam, a partir de então, pendularmente, em situações de acomodação e conflito. Se admitimos o bordão divide et regna, a centralidade, nos moldes capitalistas de sobredeterminação hegemônica, dividiu a América Latina, dificultando a integração motu proprio.

Não se entenda por aí a consagração da argumentação de André Gunder Frank (1973:27), segundo a qual a estrutura capitalista na América Latina vem desde o século XVI até o presente, com invariabilidade de algumas de suas contradições. O que é problemático em tal postura é a possibilidade de ela implicar, em algum grau, a desistoricização de estruturas ou transformação da história em uma série de permanências estruturais. Feita a ressalva, há vantagens na recuperação do passado vivo, no sentido que ele se mantém ainda eficaz, com nova e histórica eficacidade, sem exclusão do novo, mas resistindo à ruptura com o Ocidente Cristão, de que se ufanava Golbery de Couto e Silva, ideólogo da Escola Superior de Guerra (1957). Caberia dizer com Marx: não só nos atormentam os vivos, como também os mortos.

\section{Valorização Unilateral de Determinado Padrão de Análise}

Os estudos da dependência na América Latina tiveram durante o período da guerra fria indiscutível centralidade. O grande debate se instaurou a partir da fundação da Cepal, com ênfase nos limites do projeto de desenvolvimento nacional autônomo. Após os encaminhamentos de projetos de industrialização a governos, economistas da Cepal dão decisiva contribuição teórica para projetos de integração regional, a partir da segunda metade da década de 50 . O que ocorre nas décadas de 60 a 80 é o destaque para questões internas, relacionadas com o tema do desenvolvimento. Nesta mesma Revista, e em alguns outros textos, saltando de elipse em elipse do discurso integracionista latino-americanista, foi exposta a constelação dos discursos básicos de tal debate, que mudam de ênfase 
à medida que seus formuladores transitam pelas encruzilhadas deste complexo continente. Retoma-se a distinção clássica entre Teorias da Dependência e Teorias do Desenvolvimento $(1975,1995)$, com a atualização destas últimas pelos neoliberais. Enfoques mais amplos ficaram marcados pela excessiva compartimentalização, como enfatiza Oliveira (2001:49). Mais recentemente, com a criação de cursos de graduação e pós-graduação de Relações Internacionais, como que fomos pegos de calças curtas. Sem tradição de pesquisa mais elaborada no campo, verifica-se a tendência predominante nas universidades brasileiras de acompanhar de perto a produção acadêmica norte-americana, na sua vertente mais conservadora, recheada de neos. Ficam de lado vertentes mais inovadoras, lá mesmo formuladas. Acrescente-se certa desatenção com as contribuições européias, salvo em parte a inglesa, como se o processo de constituição da União Européia não tivesse suscitado estudos basilares sobre integração nos importantes centros de pesquisa da Alemanha, da França, da Itália, da Suíça. Temos, no entanto, de admitir que, pelo menos do ponto de vista quantitativo, a produção acadêmica dos Estados Unidos, no campo das Relações Internacionais, tem sido mais acurada pelo incentivo recebido. O conselho de Maquiavel ao Príncipe, de que ele conhecesse o terreno em que pisava, suscitou nos EUA polpudos investimentos nas especializações em áreas estratégicas, daí o número significativo de brasilianistas. Não parece exagerado divisar o cenário do harvardismo dos porta-fólios de nossos economistas ser clonado pelos estudos da agenda internacional de pesquisadores latinoamericanos.

Outro ponto crítico é o da suposição, de caráter corporativo, de que Relações Internacionais constituem área de saber, como postula Hoffmann (1960). Tal restrição epistemológica tem levado a dois extremos: descritivismos ou abstracionismos, neste último caso, no sentido de não-aceitação de que o real concreto está sujeito a múltiplas determinações, e que assim também ocorre com as relações internacionais. No primeiro caso, são superdimensionados os procedimentos de coleta de dados, sua ordenação como informação, nos moldes da sociologia empírica: trata-se do modelo de investigação administrativa, como a denominou T. W. Adorno, a qual prescinde da análise de pressupostos e suas conseqüências. A nosso modo de ver, há vantagens de se definir Relações Internacionais como campo de confluência de áreas de saber, para o que são bem-vindos estudos de historiadores, cientistas políticos, economistas, juristas, filósofos, sociólogos, antropólogos, psicólogos. Só dessa forma, no diálogo inter e transdisciplinar, tornamo-nos capacitados para dar conta das forças profundas que movem a história, de que nos fala Renouvin (1994), o que é retomado por Duroselle (1981), e mais sensivelmente valorizado na produção acadêmica da França. Trata-se sobretudo da crítica ao reducionismo operado pela história diplomática, tratadística, jurisdicista e factual, conforme bem acentua Saraiva (1997:21-30). Com tal orientação, não basta para a compreensão da formação dos blocos, do processo de integração, registrar apenas as iniciativas estatal e empresarial, até mesmo sindical. Não é menos importante a dinâmica, embora menos visível, de movimentos pelos quais fluem solidariedades por novos canais, externos a blocos formalizados. Cabe acentuar que uma disciplina não se constitui apenas pelo seu objeto, mas pelo trajeto teórico-metodológico adotado na análise desse objeto. No mapeamento de trajetos adotados no estudo de RI, há necessidade de ampliação da iniciativa multidisciplinar.

\section{Identidade Comprometida}

Há um tipo de discurso que busca dar visibilidade à América Latina, tornando-a dizível a partir de identidade supostamente natural. Na versão local, tem sido caracterizada, não poucas vezes, de maneira mecânica, a partir de um apriorismo geográfico. Na versão externa mais negativa, herdada do Espírito das Leis de Montesquieu, o continente é colocado em posição de subordinação disciplinada, ou na dispersão sob controle, efeito determinado pela geografia física, pelo clima do trópicos. Tem-se, neste último caso, a representação comprometida de que fala Greenblatt (1991:12-13), na qual o que é primordial não é o conhecimento do outro, mas a ação sobre o outro, a prática sobre o outro. É o discurso do colonizador, do império.

\section{Idealização Identitária}

Há o inócuo e até mesmo prejudicial discurso latinoamericanista, sujeito a impulsos emocionais. Seu mérito efetivo se reduz ao modo reativo com que se defronta com o pan-americanismo, gestado pelo destino manifesto norteamericano.

\section{Fragmentado Apelo ao Imperialismo}

Reiteram-se, neste caso, observações, colhidas do nem sempre claro apelo ao imperialismo, ora categoria econô- 
mica, ora categoria política. Tem servido como referencial teórico para a apologia do nacionalismo autarcizante, incapaz de propostas concretas de superação de rivalidades regionais, e que tampouco tem servido à proclamada exacerbação da luta de classes no continente. Não se trata de negar a categoria, mas de torná-la sujeita às vicissitudes da atual correlação de forças no mundo. ${ }^{1}$ A crescente intersecção de traços para fora/para dentro na atual cartografia mundial, a sinuosidade de interesses, aspirações, lealdades, suscitam importantes realinhamentos teóricometodológicos nas Ciências Sociais. No que mais de perto interessa neste texto, em meio ao debate sobre a qualidade do conhecimento apropriado à realidade latino-americana, é a referência às avaliações por que passa a inteligibilidade dos blocos em formação, com a relativização das soberanias nacionais, com as complexas assimetrias de nichos mais e menos desenvolvidos dentro de uma mesma nação. Como anota Pierucci (1999:170), o Ocidente se defronta com seu outro cultural em seu próprio território, dentro de suas próprias fronteiras geográficas, contrariando a tese do choque de civilizações, ersatz da bipolaridade. Essa nova realidade tem sido amplamente descrita, e analisada de forma bastante diferenciada (Resende, 2001). Há necessidade de se aprofundar o real significado do vocabulário integracionista das teorias em voga, para que o apelo à integração não opere como deusex-machina, à esquerda ou à direita. Reificado, o vocábulo integração se transforma em fator atuante nas análises, como se operasse, com certo automatismo, na direção do desenvolvimento sustentável da região, ou o seu contrário, sem que seja identificada sua natureza real. Faz-se imprescindível a decodificação das relações entre projetos integracionistas e interesses em jogo; vinculações entre o econômico, o político, o social e o cultural; imbricação de instituições e valores. Na falta de controle intelectual dessas relações, a interpretação fica à deriva de procedimentos românticos, ideológicos ou de clonagem acadêmica importada, quando não de descritivismos, à base de muita informação e precário processamento da pletora de dados à disposição.

\section{REALINHAMENTO TEÓRICO-METODOLÓGICO}

Tornou-se lugar-comum a afirmação que a aceleração exponencial na formação de blocos força a abertura do campo discursivo das ciências sociais. $\mathrm{Na}$ era dos fluxos e redes globais, a versão expandida do capitalismo simplifica o mundo pela intensificação dos capitais em movi- mento e seu séquito. Registram-se mudanças na geopolítica do conhecimento, que estão a exigir da intelectualidade novas formas de reflexão sobre a realidade de cada nação, de cada região neste processo de building block. Caso contrário, as ciências sociais se tornarão tão arcaicas quanto a alquimia.

Buscam-se sugestões nos debates, com a certeza da utilidade do confronto de idéias, como maneira eficaz de superação dos obstáculos epistemológicos, que tanto dificultam o conhecimento da complexa realidade atual. De modo seletivo, destacam-se alternativas teóricas na análise de projetos intergovernamentais e internacionais de integração, tendo como critério glosar tendências básicas, duas ou três, dentro de cada qual se situam diferentes autores com opções próximas, embora não equivalentes, pois o debate teórico-metodológico, conotando práticas, não foge à fronteira de respostas limitadas. Como não se pretende fazer exegese talmúdica de pensamentos em si, acredita-se que as vantagens de tal síntese para avaliação do conhecimento da América Latina superam a desvantagem do resvalo numa quase tipologia. Braillard (1990:18) se vê confrontado, na edição original de sua Teoria das relações internacionais em 1977, com a evolução do objeto, sua complexidade e diversidade de aspectos, que reclamam estudo pluridisciplinar. Teoricamente, ou no nível da narrativa histórica, analistas não têm economizado o uso dos prefixos neo e pós. Estamos diante de neo-realismos, neopositivismos, neofuncionalismo, neo-socialismo, neoliberalismo, pós-guerra fria, pós-moderno. Fica no ar, não poucas vezes, a oportunidade do uso do prefixo paleo ao invés do neo. O prefixo neo tem caracterizado formas de revisões nos moldes de atualização conservadora de conceitos ou de referências históricas, na dupla direção: a de integração como ameaça ou de integração como salvação. É o esforço de fazer entrar situações novas em esquemas antigos ou elaborados para outro contexto histórico.

As situações de oposição e conflito se colocam lado a lado dos intentos de cooperação e integração. Imbricamse os estudos sobre cooperação e integração com os estudos sobre estratégias de resolução dos conflitos - as vias de solução, controle e prevenção. Diferentes ênfases, nas pesquisas de integração/conflitos, são colocadas, com vista aos fatores intervenientes, aos agentes de proveniência variada e a ritmo e abrangência das relações internacionais. Basicamente, os estudos e as práticas diplomáticas latino-americanas têm estado parametrados pelo que se convencionou chamar de realismo e neoliberalismo. As 
nuanças do neo-realismo, do funcionalismo, neofuncionalismo, institucionalismo, behaviorismo, não parecem repercutir como alternativas e sim como acessórios, aperfeiçoamento na linha do Estado, como agente central na perspectiva realista, e do mercado, na perspectiva neoliberal. A fuga de tais limites seria tarefa de alguns marxistas. Estamos propondo algo mais radical, a partir de perspectiva crítica aos apelos identitários.

A escola realista e seus autores clássicos-Carr (1981), Morgenthau (1948), ou a teoria diplomático-estratégica da sociologia histórica de Aron (1979) -, têm em comum a concepção de que as relações entre as nações se estabelecem enquanto correlação de forças, com o animus dominandi, cada qual visando impor seus interesses. A ordem internacional é marcada por relação de soma zero no complicado mundo de múltiplas soberanias. É uma posição de crítica diante dos impropriamente cognominados de idealistas, melhor dizendo legalistas, pelo apelo a tratados, negociações institucionalizadas. Seu grande mentor, Woodrow Wilson, não teve êxito na proposta de criação da Sociedade das Nações, após a Primeira Guerra Mundial. O impacto de tal concepção, antes mesmo de ter sido explicitada academicamente, qualifica a prática da política externa de alinhamento da América Latina aos Estados Unidos, ao mesmo tempo que se desqualificam projetos de integração regional. Bueno (1992:168-179) fez pesquisa histórica bem respaldada em documentação sobre as visões realistas de Rio Branco e Joaquim Nabuco nos primórdios da República, claro está, em sentido de pragmatismo diplomático, sem explicitação teórica.

Para Rio Branco (1905), "a tão falada liga das repúblicas hispano-americanas, para fazer frente aos Estados Unidos, é pensamento irrealizável, pela impossibilidade de acordo entre povos em geral separados uns dos outros, e é tão ridícula, dada a conhecida fraqueza e falta de recurso de todos eles". À base do pressuposto do balance of power, esse quadro realista é completado por Bueno, citando os Discursos e conferências de Joaquim Nabuco, para quem "a América, graças à doutrina Monroe, é o Continente da Paz, e essa colossal unidade pacificadora, interessando fundamentalmente a outras regiões da Terra todo o Pacífico a bem dizer -, forma um Hemisfério Neutro e contrabalança o outro hemisfério, que bem poderíamos chamar o Hemisfério Beligerante".

Na década de 60, com a reconstrução da Europa Ocidental graças ao Plano Marshall, o realismo passa pelo crivo das críticas dos behavioristas, dentre os quais Deutsch (1966), com seu foco no crescimento das comu- nicações, conduzindo à integração por amálgama; ou Rosenau (1967), atento às ligações transnacionais. É abrandada a visão essencialista do estado-soberano e criticada a ênfase dada de modo unilateral à noção de soberania. $\mathrm{O}$ peso de variáveis econômicas, sociais, culturais na configuração da ordem internacional é incorporado às análises. De modo reativo, os neo-realistas, dentre eles Waltz (1954), Bull (1977), retomam a ênfase da centralidade do Estado na cena internacional, ao qual se subordinam atores não-estatais. Manifestam seu ceticismo quanto ao movimento de interdependência, a partir de processos econômicos transnacionais. Halliday (1999:25-26) não vê, no entanto, mesmo no caso do behaviorismo, de espectro ampliado na análise da realidade internacional, uma alternativa, e sim um acessório, com relação à abordagem centrada no Estado. Em suma, persiste a margem significativa de limitações a qualquer interpretação da realidade internacional baseada na solidariedade.

A releitura neo-realista e a crítica behaviorista abriram, no entanto, possibilidade para nova variedade de subcampos nos ramos da análise de política externa, da interdependência e da economia política internacional. Nessa mesma linha de entornos do realismo, a teoria funcionalista de integração, em sua formulação primeira, valoriza a cooperação em vez da integração. Vale dizer, é ciosa da manutenção das soberanias nacionais. De modo pragmático, coloca-se diante de tarefas de natureza técnica na solução de problemas de caráter econômico. A paz se constrói na busca de solução para questões concretas diante de necessidades, não a priori, no campo dos valores. Exclui-se o apelo à institucionalização no plano político, como forma de preservação das soberanias nacionais. Isso quer dizer que um de seus princípios básicos é o da nãoterritorialidade da autoridade, cuja competência se esgota no exercício de determinada atividade. Dentre os teóricos clássicos de tal posicionamento, destaca-se Mitrany (1943).

O que nos parece de interesse na revisão da teoria funcionalista, sob a rubrica do neofuncionalismo de Haas (1958), é o pressuposto da ramificação. O processo de cooperação se amplia, cronologicamente, com a sucessão de novas demandas, em grau crescente. Instauram-se práticas governamentais e societárias de ampliação da cooperação diante de necessidades concretas, que passam a encontrar, com tais procedimentos, o melhor caminho de solução, na medida em que surgem. Os desdobramentos da Comunidade Européia do Carvão e do Aço levam os neofuncionalistas a se colocarem diante do processo que, 
de modo germinal, vai supondo o surgimento de novo centro decisório, órgão central de integração, ao qual se confere a atribuição de decisões obrigatórias, o que marca a diferença fundamental da teoria neofuncionalista e da teoria funcionalista de integração: no último caso, a autoritas, à frente da cooperação, não se territorializa enquanto potestas; naquele, ela se territorializa, com a construção gradual de aparatos institucionais centralizados, de caráter não apenas econômico, mas também político (Lindberg, 1963). Essa perspectiva tem como ponto positivo ser capaz de dar conta de vários agentes de integração. Consegue acompanhar, dando peso, os acontecimentos que se passam fora do âmbito das iniciativas estatais e de seu controle direto. Seu grande limite é o de seqüenciá-los, com ênfase no elenco cronológico de demandas e respostas. O que de fato parece estar ocorrendo é que, à medida que o processo se desencadeia, há uma constelação de agentes que operam simultaneamente e não apenas em tempos sucessivos. Oliveira e Sennes ( 2001:71-110) fazem, na linha do neofuncionalismo, o que denominam de análise sincrônica da integração, a passagem do etapismo dos neofuncionalistas - a integração num crescendo - para a integração aberta às opções dos agentes de integração, simultaneamente. Partem da hipótese de que os atores envolvidos abrigam percepções distintas sobre a natureza do processo, as motivações dos outros atores envolvidos e suas próprias prioridades políticas e econômicas, sem que isso obstaculize a acomodação de interesses.

De modo imbricado com o que se denomina, sem maior precisão de globalização, o paradigma da interdependência complexa veicula a categoria de regime internacional em substituição ao sistema internacional de Estados como estrutura básica da ordem mundial: há uma rede de normas, regras e procedimentos que os players internacionais, de diversas origens, levam em conta em suas relações. Nye (2002) reitera, após o 11 de setembro, o fato de a unipolaridade do poder dos Estados Unidos e a multipolaridade econômica, estabelecida entre os países de capitalismo de ponta, serem atravessadas pela transnacionalidade de relações, que fronteiras, fora do controle de governos, de modo isolado. Vínculos cooperativos se estabelecem, o que faz, em caso de conflito, que a solução seja encontrada no âmbito da negociação entre Estados, empresas, organismos internacional, etc., fora do âmbito político-militar. Nye (2002:140) enfatiza a possibilidade de consolidação da hegemonia dos Estados Unidos, através do equilíbrio de seu hard power, com dose crescente de soft power: "isto significa que meio milhão de estu- dantes estrangeiros querem estudar nos Estados Unidos a cada ano, europeus e asiáticos querem assistir filmes e TV americanos, que as liberdades americanas são atrativo em muitas partes do mundo, e que outros nos respeitam e desejam a liderança norte-americana, quando 'we are not too arrrogant'". O foco de tal análise tende a sofisticar assimetrias, que perpassam essas mesmas relações e as tenções permanentes daí decorrentes, mesmo que atenuadas pelo soft power.

O neoliberalismo retoma o velho encanto dos paleoliberais com o mercado e o desencanto com o Estado. O fracasso do Plano na URSS é assumido como prova de que o mercado deve ser aceito como principal motor da nova ordem internacional, desde que não se lhe anteponham as arcaicas políticas sociais do Welfare State. O mercado se apresenta como tendo potencialidades não imaginadas pelos paleoliberais. Por essa via expressa e mundial, circulariam confortável e velozmente compradores e vendedores, sem os entraves das lombadas alfandegárias das estreitas vias locais e estatais. O receituário neoliberal, última versão, foi exportado para a América Latina com as teses do Consenso de Washington, hoje avaliado pelos seus próprios autores de modo relativamente severo. A expressão foi forjada pelo economista John Williamson em 1989. Trata-se da estratégia de ajustamento e estabilização das economias dos países periféricos, formulada pelo governo americano, o FMI e o Banco Mundial. Baseia-se na redução do tamanho do Estado através de privatizações, no fim do déficit nas contas públicas e na abertura dos mercados nacionais, com o objetivo de obter a retomada dos investimentos externos para alavancar o crescimento econômico.

O tertium quid teórico, ultrapassando a alternativa realismo ou neoliberalismo, com as gradações intermediárias, tem sido rotineiramente posto pelas várias vertentes saídas do marxismo, em baixa ou em crise de reformulação no continente, após o desmoronamento da União Soviética. Interessam mais de perto as atuais reformulações da categoria de imperialismo. O debate mais tradicional, e de menor interesse no presente, centrava-se na caracterização mais precisa do que se entendia por imperialismo, categoria que, pendularmente, movimentava-se entre o político, o econômico e o cultural, sem que se determinasse a imbricação ou não destes âmbitos na mesma categoria. Importantes reformulações destacam não apenas o papel desempenhado pela estrutura socioeconômica, como a maior atenção com aspectos políticos, colhidos das tradições da democracia representativa, e culturais. 


\section{DESCONSTRUÇÃO DAS POLÍTICAS IDENTITÁRIAS}

Teórica e metodologicamente, o desafio é de desconstrução da precária lógica de políticas identitárias. ${ }^{2}$ As identidades ancestrais, as solidariedades, definidas de modo essencialista, têm apenas função reativa. Parece-nos oportuna a relativização e, em alguns casos, até mesmo a deslegitimação de tradições ou práticas geopolíticas, que emperram irrupções a favor de novos trajetos, como desdobramento de potencialidades. Não é descartável o reforço de movimentos de desidentificação com memórias nacionais. Desfazem-se, dessa forma, noções essencialistas, que atravessam os discursos instituintes da idéia de América Latina. O geografismo força os que a habitam à latino-americanização, no momento mesmo em que os latino-americaniza ou ibericiza. Doutra parte, é recurso tático não desprezível de negociação a flexibilização da política identitária, determinada pela Deusa Fortuna, com exaltação da Virtù da boa vizinhança, de modo confuso. Contra afirmações autarcizantes de autopresença nacional no contexto mundial, é uma forma tática de enfrentar a globalização neoliberal. No entanto, torna-se recurso no mínimo ambíguo, quando se lhe confere função estratégica. O conhecimento latino-americanista, segundo Moreiras (2001:10), num primeiro sentido, aspira à forma particular do poder disciplinar, herdado do aparato hegemonizante do estado imperial. É conhecimento que opera como instância da agência global. Nascido da ideologia da diferença cultural, seu impulso fundamental é de captar a diferença latino-americana, a fim de lançá-la na grade epistêmica global. É conhecimento que azeita a máquina de homogeneização, mesmo nas ocasiões em que julga estar promovendo ou preservando a diferença. As diferenças latino-americanas são controladas, homogeneizadas e colocadas a serviço da representação global. O conhecimento latino-americanista, entendido nesse primeiro sentido, busca sua própria negação e se dissolve dentro do panóptico. Os diagramas disciplinares em geral funcionam, basicamente, em posições determinadas, pontos fixos em que se compõem, de modo impositivo, as identidades. Foucault ${ }^{3}$ via a produção de identidades, mesmo as oposicionistas ou desviadas, como fundamentais para funções de domínio em sociedades disciplinares. O par centro-periferia, sujeito à polaridade dentro/ fora, leva-nos a pensar a América Latina, até o momento presente, fora das benesses da modernidade modernizante, o que legitima a percepção da dicotomia países desenvol- vidos/países subdesenvolvidos ou, eufemisticamente, chamados "em vias de desenvolvimento", como se fossem potências médias.

\section{LATINO-AMERICANISMO SUBVERTIDO DE MODO ANTIDISCIPLINAR}

Há, no entanto, brechas para se pensar o latinoamericanismo de modo alternativo, subvertido de modo antidisciplinar. Por esse trajeto, desarticulam-se diferenças e identidades (Hardt, 1995:34-36). O diagrama do controle não está orientado na direção da posição e da identidade, mas da mobilidade e da anonimidade. Nesse caso, registra-se atuação flexível e instável de identidades contingentes, através da repetição e da produção de simulacros. Enquanto das janelas do panóptico capturam-se posições, pontos fixos, identidades, nas sociedades de controle decreta-se a falência da sociedade civil, que se torna sociedade política, com surgimento do Estado global. Império é o nome dado por Hardt à sociedade global de controle. Empalidecem as fronteiras territoriais, sem que se registrem conquistas. Os elementos de transcendência da sociedade disciplinar declinam, enquanto os aspectos imanentes são acentuados e generalizados. Segundo Hardt e Negri (2001:338), no espaço regular do império, não há nenhum lugar de poder, que está em todo lugar e em lugar nenhum. Acaba, nem que seja gradualmente, ou se atenua a polarização centro/periferia - os antigos pontos fixos. É um "Império sem Roma: na transição da soberania para o plano de imanência, o colapso das fronteiras teve lugar dentro de cada contexto nacional e em escala global. (...) a crise geral das instituições disciplinares coincide com o declínio dos Estados-nação como fronteiras que marcam e organizam as divisões no governo global. O estabelecimento de uma sociedade global de controle que suavize as estrias das fronteiras nacionais anda junto com a realização do mercado mundial e a submissão da sociedade global ao capital" (Hardt e Negri, 2001:354).

Na superfície lisa de intersecção, a pretensão é se discutirem as reais possibilidades de se colocar, por fora desses discursos de poderes, o imperial, o regional e o nacional, versões disciplinares e versões de controle. Passa-se então a ter como referente primário não as identidades nativas, os Estados nacionais ou o sistema interestatal latino-americano, supervisionados pelo pan-americanismo, filho pródigo do monroísmo.

Com efeito, os Estados nacionais no sistema internacional estão deixando de ser o local onde o saber e o poder 
se encontram na definição do valor social. Deleuze e Guattari falam de desterritorialização. Moreiras (2001:112) fala de desreferencialização da cultura. À medida que o capital se desprende de seu momento produtivo, ele abandona o solo e, literalmente, levanta vôo.

$\mathrm{Na}$ linha de tal reflexão, trata-se sobretudo de caracterizar, com um mínimo de clareza e objetividade, o latinoamericanismo do ângulo da globalização, seja como sistema global do capital, operando como on, it, numa esdrúxula descentralização, seja como alternativa horizontalizante.

No primeiro caso, o eixo de raciocínio dos intelectuais institucionais da América Latina sujeita-se à severa avaliação de alguns poucos. Moreiras (2001:41-42) reproduz as críticas de Petras, Morley, Rafael, aos que escrevem para outros intelectuais institucionais e trabalham dentro das fronteiras destes, seus patrocinadores estrangeiros instituições financiadoras, seus congressos internacionais. ( ...) os estudos da área têm se integrado a redes institucionais mais amplas, (...) que tornaram possível a reprodução de um estilo norte-americano de conhecimento, (...) seguiram uma lógica integracionista, pela qual se faz coincidir a função conservadora dos estudos.

Quanto à globalização alternativa, horizontalizante, por fora das crostas identitárias nacionais e regionais, em tal caso, a crítica divisa aí ato de abdicação de toda a história, desde o período colonial, que lhe teria outorgado a identidade no âmbito que pertença ao Ocidente. É a desconstrução de codificações impositivas, a favor da reinvenção da América Latina mestiça (Resende, 2001), capaz de não apenas se redefinir, mas ir mais longe, em novos fluxos civilizatórios, de dimensão planetária, com novas possibilidades para as forças de liberação. Tem-se preferido a categoria de mestiçagem, sem casa grande e senzala, como referência à natureza plural das sociedades contemporâneas, cujas relações em rede colocam em relevo a dimensão econômica, política, social e cultural de desidentificações. Problematizamos, ademais, as categorias de multiculturalismo e tolerância, tidas como insuficientes ou inadequadas para acompanhar a emergência de novas formas de conectividade social. Moriconi (2001:74), na mesma direção, enfatiza o fato de que identidade só existe em situações muito estabilizadas. Caso contrário, seriam dadas identificações cambiantes, ou seja, identificações que são simultaneamente vivências de desidentificação. Desloca então o eixo de seu raciocínio da categoria de identidade para a de posicionalidade, que se traduz na dialética do par identidade-desidentidade, ou ainda, no perene movi- mento de identificações e desidentificações. O bordão pense globalmente, aja localmente tem, nesta maneira de pensar, a nova realidade, a inadequação de repor o dualismo do global e do local. Ao contrário, as redes de relações nos vários níveis da convivência humana entre os povos estão a exigir uma resposta global alternativa. A resposta local é insuficiente, e Cuba o comprova, ${ }^{4}$ conforme acentua Hardt em sua entrevista ao jornal Folha de S.Paulo, os movimentos de protesto são indicadores de uma conexão que existe entre as pessoas de partes diferentes do mundo, de uma potencial convergência de interesses que ultrapassam situações locais. Não estamos mais diante do imperialismo, que supõe a expansão do Estado-Nação hegemônico. O império é uma forma política que não tem confins, forças localizadas, como o Estado-Nação. O império manda para os ares os conceitos de nação, raça, etnia, e até de povo. Para Hardt e Negri, em Império, precisamos de novas formas de solidariedade internacional, de culturas híbridas para enfrentar o império por fora dos mecanismos de representação.

Nessa linha de raciocínio, cabe redefinir o que vem a ser latino-americano hoje: caberia admitir a fragilidade da dialética entre a interioridade continental e a exterioridade imperial, como se esta última operasse de fora, nos moldes das teorias da dependência dos anos 50, 60, 70, no contexto da guerra fria, na vigência do imperialismo disciplinar. Centro e periferia são categorias espaciais fragilizadas na atualidade, um modelo arquitetônico de mundo que pressupõe a rígida divisão internacional do trabalho, e fronteiras ideológicas do mundo bipolar, que mal acompanha hoje os movimentos do capital, que já Marx supusera tendencialmente apátrida. Encontramo-nos diante de processos de desterritorializações que nos desafiam a traçar nova cartografia com a mistura de lugares, com novas confluências. O controle imperial, no lugar da disciplina recheada de lugares e identidades, é desconcertante para a construção de cenários de resistência. É, no entanto, a maneira mais apropriada de descobrir meios adequados de luta, o que já mostra seu fluxo em Seattle, Davos, Praga, Gênova e Porto Alegre, de forma bastante híbrida, portanto atual. Assistimos no presente ao advento dos novos bárbaros, a ver caminhos por toda parte, o que supõe, na bela e desafiadora imagem de Hardt e Negri (2001:235), de estarmos chamados a nos colocar em encruzilhadas. Incluam-se as da América Latina e do Brasil. Não são vias fáceis, mas tampouco o eram as antigas. A dinâmica das mestiçagens é colocada em contraposição, de um lado, com afirmações hegemônicas e uniformizan- 
tes e, de outro, contra fundamentalismos, relativismos e nacionalismos. Velha nossa conhecida, a mestiçagem de corpos, mas, sobretudo, cabe falar da mestiçagem de representações, de códigos, de práticas, de gostos, de crenças. A criatividade local, regional, passa por aí e se afirma não como entrave, mas diferencial, valorizado pela inserção positiva na realidade transnacional mais ampla.

\section{NOTAS}

1. Deve-se ter alguma precaução em afirmar a hegemonia dos EUA, em que pesem sua economia e sua tecnologia. Se por hegemonia entendemos coerção + consenso, há várias manifestações em contrário, e não como protestos isolados.

2. Ultrapassa as intenções do presente texto discutir a tese de Cuche (1999). O autor assume o relativismo cultural e o etnocentrismo como princípio metodológico. A utilização combinada, segundo o autor, do que seria aparentemente contraditório, permitiria a ele apreender a dialética do igual e do outro, da identidade e da diferença, ou seja, da Cultura e das Culturas, como fundamento da dinâmica social. Admitamos que em nome da dialética têm-se resolvido aporias, que deixam em suspenso qualquer filosofia, mesmo tendo como respaldo Bourdieu, Pierre Jean Simon.

3. Na produção da identidade, na perspectiva de Foucault, estão em ação uma técnica, um dispositivo, um mecanismo, um instrumento de poder, métodos que permitem o controle minucioso das operações do corpo, que asseguram a sujeição constante de suas forças e lhes impõem uma relação de docilidade-utilidade.

4. Nas práticas diplomáticas da América Latina, tem imperado a problemática exclusão de Cuba em importantes reuniões de cúpula, por exigência unilateral dos EUA e contínua pressão para que tal comportamento seja legitimado pelos demais países do continente, o que não tem encontrado resistências decisivas. É, na melhor das hipóteses, atitude insólita, levando-se em conta a legitimação anterior dos Trujillos e Batistas.

\section{REFERÊNCIAS BIBLIOGRÁFICAS}

ARON, R. Paz e guerra entre as nações. Brasília, UNB, 1979.

BRAILLARD, P. Teoria das relações internacionais. Lisboa, Fundação Caloouste Gulbenkian, 1990.

BUENO, C. "O Brasil e o subsistema norte-americano de poder". In: CERVO, A.L. e BUENO, C. História da politica exterior do Brasil. São Paulo, Ática, 1992.

BULL, H. The anarchical society. Oxford, Ox. Univ. Press, 1977.

CARR, E.H. Vinte anos de crise: 1919-1939. Brasília, UNB, 1981.

COUTO E SILVA, G. do. Aspectos geopolíticos do Brasil. Rio de Janeiro, Biblioteca do Exército, 1957.

CUCHE, D. A noção de cultura nas ciências sociais. Bauru, Edusc, 1999.

DEUTSCH, K. International political communities: an anthology. Garden City, Anchor Books, 1966.

DUROSELLE, J.-B. Tout empire périra - une vision théorique des relations internacionales. Paris, Publications de la Sorbonne, 1981.

FRANK, A.G. Capitalismo y subdesarrollo em America Latina. $2^{\mathrm{a}}$ ed., Buenos Aires, Siglo Veintiuno, 1973.
GREENBLATT, S. Marvellous possessions. The wonder of the new world. Chicago, University of Chicago Press, 1991, p.12-3.

HAAS, E. The uniting of Europe. Stanford, Stanford University Press, 1958.

HALLYDAY, F. Repensando as relações internacionais. Porto Alegre, Ed. da Universidade, 1999.

HARDT, M. The withering of civil society. Social Text, n.45, Winter, 1995.

HARDT, M. e NEGRI, A. Império. Rio de Janeiro, Record, 2001.

HOFFMANN, S. (org.). Contemporary theory in international relations. Englewood Cliffs, NJ, Prentice Hall, 1960.

LINDBERG, L.N. The political dynamics of european economic integration. Oxford, London University Press, 1963.

MITRANY, D. A working peace system. Londres, Royal Institute of International Affairs, 1943.

MOREIRAS, A. A exaustão da diferença. A política dos estudos culturais latino-americanos. Belo Horizonte, Editora UFMG, 2001.

MORGENTHAU, H.J. Politics among nations. The struggle for power and peace. Nova York, Alfred Kopf, 1948.

MORICONI, Í. “A outra dimensão: desidentidades". In: TORRES, S. (org.). Raizes e rumos - Perspectivas interdisciplinares em estudos americanos. Rio de Janeiro, 7 Letras, 2001.

NYE Jr., J.S. The paradox of American Power. Why the world's only superpower can't go it alone. Nova York, Oxford University Press, 202.

OLIVEIRA, A.J. e SENNES, R.U. "Teoria sincrônica da integração regional: matrizes teóricas e percepção das elites do Mercosul”. Contexto Internacional. Rio de Janeiro, PUC, v.23, n.1, jan.-jun. 2001.

OLIVEIRA, O.M. Relações internacionais - Estudos de introdução. Curitiba, Ed. Juruá, 2001.

PIERUCCI, A.F. Ciladas da diferença. São Paulo, Ed. 34, 1999.

RENOUVIN, P. (org.). Histoire des relations internationales. Paris, Hachette, 1994.

RESENDE, P.-E.A. "Contribuição teórico-metodológica para o estudo dos padrões de integração-dominação da América Latina e suas repercussões na Alalc. Tese de doutorado. São Paulo, PUC-SP, 1975.

.Novas formas de integração". São Paulo em Perspectiva. São Paulo, Fundação SEADE, v.9, n.1, 1995.

"Comunicação e mestiçagem". In: DOWBOR, L.; IANNI, O. e RESENDE, P.-E.A. Desafios da comunicação. Petrópolis, Vozes, 2001.

ROSENAU, J.N. Domestic source of foreign policy. Nova York, The Free Press, 1967.

SARAIVA, J.F.S. "A escola francesa". In: ___ (org.). Relações internacionais contemporâneas. Da construção do mundo liberal à globalização - de 1815 a nossos dias. Brasília, Paralelo 15, 1997.

STANLEY, J. (org.). Contemporary theory in international relations. Englewood Cliffs, NJ, Prentice Hall, 1960.

WALTZ, K. Man, the state and war. Nova York, Columbia University Press, 1954.

WENDT, A. "The agent-structure problem in international relations theory”. International Organization v.41, n.3, 1987.

Paulo-Edgar Almeida Resende: Professor da área de concentração de Relações Internacionais do Programa de Pós-Graduação de Ciências Sociais PUC-SP e membro do GACINT-USP. 